\title{
HUBUNGAN LAMA PENGGUNAAN ALAT ORTODONTIK CEKAT TERHADAP AKUMULASI PLAK DAN PH SALIVA MAHASISWA FKG-UMI TAHUN 2017
}

\author{
Nurasisa Lestari, Yustisia Puspitasari, Tri Audia Masdar
}

Fakultas Kedokteran Gigi Universitas Muslim Indonesia, Makassar Email: nurasisal@gmail.com.

\begin{abstract}
Orthodontic treatment is a form of treatment in the field of dentistry which plays an important role in improving dental structure. Fixed orthodontic tools have an important role to obtain optimal and harmonic occlusion. Orthodontic appliance also affects plaque accumulation and salivary $\mathrm{pH}$ so that it can cause various dental and oral diseases The purpose of this study was to determine the relationship between the length of fixed orthodontic use to plaque accumulation and salivary $\mathrm{pH}$ of FKG UMI students in 2017. This study was an analytic observational, cross sectional study method. The sample of this study was FKG UMI students who used fixed orthodontics, sampling techniques with total sampling.Statistical test used Independent Samples Test. The results of this study showed $<12$ months long fixed orthodontic use of $30.8 \%$ and> 12 months of $69.2 \%$. Based on plaque accumulation the highest score was $74.4 \%$. Based on salivary pH the highest score is acid $94.9 \%$, and based on statistical tests obtained a significant value of $p=0.001(<\alpha=0.05)$. The results showed that there was a correlation between the length of fixed orthodontic use of plaque accumulation and salivary pH of FKG-UMI students in 2017.
\end{abstract}

Key words: Fixed orthodontic appliance, accumulation plaque, saliva pH.

\section{PENDAHULUAN}

Kesehatan gigi dan mulut merupakan bagian dari kesehatan tubuh yang tidak dapat dipisahkan satu dengan yang lainya, karena akan mempengaruhi kesehatan tubuh secara keseluruhan. Gigi berperan penting dalam proses pengunyahan, berbicara dan mempengaruhi bentuk muka, sehingga adanya masalah gigi akan dapat mengganggu fungsi peran gigi. ${ }^{1}$ Perawatan ortodontik merupakan salah satu bentuk perawatan dalam bidang kedokteran gigi yang berperan penting untuk memperbaiki susunan gigi sehingga dapat meningkatkan kemampuan mastikasi, fonetik, serta estetik. Tujuan ortodontik untuk memperoleh oklusi yang optimal dan harmonis, baik letak maupun fungsinya serta untuk menciptakan keseimbangan antara hubungan oklusi gigi geligi estetik wajah dan stabilitas hasil perawatan. Alat ortodontik terdiri dari tiga jenis yaitu lepasan, cekat dan fungsional. $^{2}$ 
Hubungan lama penggunaan alat ortodontik cekat terhadap akumulasi plak dan ph saliva mahasiswa FKG-UMI tahun 2017

Saliva sebagian besar berfungsi menjaga keseimbangan didalam mulut, terutama terhadap faktor-faktor yang menyebabkan kerusakan gigi seperti karies gigi. Keasaman $\mathrm{pH}$ saliva merupakan salah satu faktor penting yang dapat mempengaruhi proses terjadinya demineralisasi pada permukaan gigi. Perawatan ortodontik baik pengguna alat ortodontik cekat atau lepasan, dapat menyebabkan perubahan yang spesifik di dalam rongga mulut termasuk berubahnya akumulasi biofilm, dan kandungan bakteri yang tinggi dalam saliva. Aktivitas bakteri di dalam plak yang dapat mempengaruhi perubahan $\mathrm{pH}$ di dalam rongga mulut dengan menghasilkan penurunan $\mathrm{pH}$ yang cepat, kemudian dalam beberapa waktu $\mathrm{pH}$ kembali ke awal secara lambat. Hal ini memicu landasan plak dan campuran bakteri yang terlibat sebagai proses penyebab karies. ${ }^{1,3}$

Penggunaan ortodontik dapat menginduksi perubahan lingkungan rongga mulut, peningkatan jumlah bakteri, perubahan kapasitas buffer saliva, derajat keasaman saliva, dan laju aliran saliva. Hasil dari penelitian yang dilakukan oleh Carillo, 2010, dkk mengatakan bahwa perawatan dengan menggunakan ortodontik cekat dapat merubah keadaan rongga mulut, meningkatkan $\mathrm{pH}$ saliva selama perawatan ortodontik. Perawatan ortodontik tetap direkomendasikan akan tetapi tetap menjaga kesehatan rongga mulut. ${ }^{4}$

Menurut penelitian yang dilakukan oleh Jayanti Amaliah Triana di Fakultas Kedokteran Gigi Universitas Muslim Indonesia pada tahun 2017 menunjukkan adanya hubungan lama pengguna piranti ortodontik cekat dengan status dan kebutuhan perawatan ortodontik. Hal ini disebabkan karena penempatan piranti ortodontik cekat dapat terbentuk tempat retensi plak disekitar bracket, sehingga jumlah plak dan bakteri anaerob dapat meningkat. ${ }^{5}$

\section{METODE PENELITIAN}

Penelitian ini dilakukan di Fakultas Kedokteran Gigi Universitas Muslim Indonesia (FKG-UMI) dan Fakultas Kedokteran Universitas Muslim Indonesia (FK-UMI) Kota Makassar bulan Oktober-Desember Tahun 2017. Subjek/Objek Penelitian yaitu mahasiswa Fakultas Kedokteran Gigi Universitas Muslim Indonesia. Teknik pengambilan sampel yang digunakan yaitu total sampling yaitu pengambilan seluruh sampel yang 
Hubungan lama penggunaan alat ortodontik cekat terhadap akumulasi plak dan ph saliva mahasiswa FKG-UMI tahun 2017

memenuhi kriteria sampel yang dibutuhkan untuk penelitian. Alat yang digunakan, Alat diagnostik, Nierbekken, handscoen, Masker, Wadah disclosing solutions, Lembar OPI (orthodontic plaque index), $\mathrm{pH}$ meter, Timbangan digital, Tabung reaksi. Rak tabug reaksi, Bahan cotton bud dan disclosing solutions.

\section{Prosedur penelitian}

\section{Pengisian Informed Consent,} Sampel peneliti diminta untuk menampung saliva dengan menggunakan tabung reaksi. selanjutnya berkumur kemudian isolasi daerah yang akan diberikan disclosing solution. Gunakan disclosing solution pada gigi yang akan akan dilakukan pemeriksaan. Menilai Indeks plak OPI (orthodontic plaque index) pada pengguna ortodontik cekat dengan skor, bila tidak adanya plak di sekitar bracket diberi skor 0 , bila plak menempel pada satu permukaan gigi di dasar bracket diberi skor 1, bila plak menempel pada dua permukaan gigi di dasar bracket diberi skor 2, bila plak menempel pada tiga permukaan gigi di dasar bracket diberi skor 4, bila plak menempel pada empat permukaan gigi di dasar bracket, dan atau indikator inflamasi gingiva diberi skor 4. Setelah selesai sampel di instruksikan untuk sikat gigi.

\section{HASIL PENELITIAN}

Tabel 1. Distribusi dan Frekuensi Lama Penggunaan Alat Ortodontik Cekat di FKG-UMI Tahun 2017

\begin{tabular}{ccc}
\hline Lama Penggunaan Alat Ortodontik Cekat & Frekuensi & $\%$ \\
\hline$\leq 12$ bulan & 12 & $30,8 \%$ \\
$>12$ bulan & 27 & $69,2 \%$ \\
\hline Total & $\mathbf{3 9}$ & $\mathbf{1 0 0} \%$ \\
\hline
\end{tabular}

Sumber : Data Primer, 2017

Tabel 2. Distribusi dan Frekuensi Akumulasi Plak Pada Penggunaan Alat Ortodontik Cekat di FKG-UMI Tahun 2017

\begin{tabular}{ccc}
\hline Orthodontic Plaque Index & Frekuensi & $\%$ \\
\hline Baik & 10 & $25,6 \%$ \\
Sedang & 29 & $74,4 \%$ \\
Buruk & - & - \\
\hline Total & $\mathbf{3 9}$ & $\mathbf{1 0 0} \%$ \\
\hline
\end{tabular}

Sumber : Data Primer, 2017 
Hubungan lama penggunaan alat ortodontik cekat terhadap akumulasi plak dan ph saliva mahasiswa FKG-UMI tahun 2017

Tabel 3. Distribusi dan Frekuensi pH Saliva Pada Penggunaan Alat Ortodontik Cekat di FKG- UMI Tahun 2017

\begin{tabular}{ccc}
\hline pH Saliva & Frekuensi & $\%$ \\
\hline Normal & 2 & $5,1 \%$ \\
Asam & 37 & $94,9 \%$ \\
Basa & - & - \\
\hline Total & $\mathbf{3 9}$ & $\mathbf{1 0 0} \%$ \\
\hline
\end{tabular}

Sumber : Data Primer, 2017

Tabel 4. Hubungan Lama Penggunaan Alat Ortodontik Cekat Terhadap Akumulasi Plak di FKG-UMI Tahun 2017

\begin{tabular}{|c|c|c|c|c|c|c|c|c|c|c|}
\hline \multirow{3}{*}{ Variabel } & & \multicolumn{8}{|c|}{ Orthodontic Plaque Index } & \multirow{3}{*}{$\begin{array}{c}P \\
\text { Value }\end{array}$} \\
\hline & & \multicolumn{2}{|c|}{ Baik } & \multicolumn{2}{|c|}{ Sedang } & \multicolumn{2}{|c|}{ Buruk } & \multicolumn{2}{|c|}{ Total } & \\
\hline & & $\mathbf{n}$ & $\%$ & $\mathbf{n}$ & $\%$ & $\mathbf{n}$ & $\%$ & $\mathbf{n}$ & $\%$ & \\
\hline \multirow{2}{*}{$\begin{array}{l}\text { Lama Penggunaan } \\
\text { Alat Ortodontik }\end{array}$} & $\begin{array}{l}\leq 12 \\
\text { bulan }\end{array}$ & 6 & 15,4 & 6 & 15,4 & - & - & 12 & 30,8 & \multirow{3}{*}{0,044} \\
\hline & $\begin{array}{l}>12 \\
\text { bulan }\end{array}$ & 4 & 10,3 & 23 & 59,0 & - & - & 27 & 69,2 & \\
\hline Total & & 10 & 25,7 & 29 & $\mathbf{7 4 , 4}$ & - & - & 39 & 100 & \\
\hline
\end{tabular}

Sumber : Data Primer, 2017

Tabel 5. Hubungan Lama Penggunaan Alat Ortodonti Cekat Terhadap pH Saliva di FKG-UMI Tahun 2017

\begin{tabular}{|c|c|c|c|c|c|c|c|c|c|c|}
\hline \multirow{3}{*}{ Variabel } & & \multicolumn{8}{|c|}{ Orthodontic Plaque Index } & \multirow{3}{*}{$\begin{array}{c}P \\
\text { Value }\end{array}$} \\
\hline & & \multicolumn{2}{|c|}{ Baik } & \multicolumn{2}{|c|}{ Sedang } & \multicolumn{2}{|c|}{ Buruk } & \multicolumn{2}{|c|}{ Total } & \\
\hline & & $\mathrm{n}$ & $\%$ & $\mathbf{n}$ & $\%$ & $\mathbf{n}$ & $\%$ & $\mathbf{n}$ & $\%$ & \\
\hline \multirow{2}{*}{$\begin{array}{l}\text { Lama Penggunaan } \\
\text { Alat Ortodontik }\end{array}$} & $\begin{array}{l}\leq 12 \\
\text { bulan }\end{array}$ & 1 & 2,6 & 11 & 28,2 & - & - & 12 & 30,8 & \multirow{3}{*}{0,001} \\
\hline & $\begin{array}{l}>12 \\
\text { bulan }\end{array}$ & 1 & 2,6 & 26 & 66,7 & - & - & 27 & 69,2 & \\
\hline Total & & 2 & 5,1 & 37 & 94,9 & - & - & 39 & 100 & \\
\hline
\end{tabular}

Sumber : Data Primer, 2017

\section{PEMBAHASAN}

Berdasarkan hasil penelitian mengenai hubungan lama penggunaan alat ortodontik cekat terhadap akumulasi plak dan $\mathrm{pH}$ saliva mahasiswa Fakultas Kedokteran Gigi Universitas Muslim Indonesia. Menurut tabel 4. didapatkan hasil pemeriksaan menggunakan Orthodontic Plaque Index pada mahasiswa Fakultas Kedokteran Gigi Universitas Muslim
Indonesia menunjukkan bahwa lama penggunaan alat ortodontik $\leq 12$ bulan yaitu sebesar (15,4\%) memiliki skor Orthodontic Plaque Index tergolong baik, (15,4\%) tergolong sedang, dan $(0 \%)$ tergolong buruk, sedangkan yang menggunakan alat ortodonti $>12$ bulan yaitu sebesar (10,3\%) memiliki skor Orthodontic Plaque Index tergolong baik, $\quad(59,0 \%)$ memiliki skor Orthodontic Plaque Index tergolong 
Hubungan lama penggunaan alat ortodontik cekat terhadap akumulasi plak dan ph saliva mahasiswa FKG-UMI tahun 2017

sedang, dan (0\%) tergolong buruk. Berdasarkan hasil uji statistik dengan menggunakan uji Independent Samples Test, diperoleh nilai $p=0,044$ $(<\alpha=0,05)$, dengan demikian diputuskan bahwa $\mathrm{H}_{0}$ ditolak dan $\mathrm{H}_{a}$ diterima yang artinya ada hubungan lama penggunaan alat ortodontik cekat terhadap akumulasi plak mahasiswa FKG-UMI Tahun 2017.

Pada penelitian ini akumulasi plak sangat banyak di dapatkan pada lama penggunaan ortodontik cekat $>12$ bulan, hal ini dapat terjadi karena ortodontik memiliki komponenkomponen ortodontik yang banyak seperti komponen aktif dan pasif, sehingga penggunaa ortodontik cekat lebih sukar dalam membersihkan gigi dan mulutnya. Pengguna ortodontik cekat sangat rentan mengalami kebersihan mulut buruk yang diakibatkan oleh meningkatnya akumulsi plak, sehingga dapat mempengaruhi kesehatan jaringan periodontal.

Hasil penelitian ini sejalan dengan penelitian yang dilakukan sebelumnya menunjukkan hasil durasi perawatan ortodontik yang lebih lama berpengaruh terhadap plak, dan gingivitis. Hal ini disebabkan karena setelah penempatan ortodontik cekat dapat menginduksi perubahan lingkungan rongga mulut, dengan peningkatan konsentrasi bakteri, keasaman $\mathrm{pH}$, tingkat cairan saliva dan potensi kerusakan pada gigi dan jaringan periodontal. Misalnya menjaga kebersihan mulut yang sulit dilakukan selama perawatan yang dapat menyebabkan akumulasi plak dan inflamasi gingival. Pasien penggunaan alat ortodontik cekat sering mengeluhkan kesulitan dalam membersihkahkan gigi geliginya. Kesulitan dalam membersihkan gigi dapat meningkatkan akumulasi plak. 4,6

Alat ortodontik cekat memiliki bentuk yang rumit sehingga pasien yang menggunakan alat ortodontik cekat sulit untuk menjaga kebersihan mulut karena akumulasi bakteri mudah terbentuk disekitar komponenkomponen alat ortodontik cekat. Penggunaan alat ortodontik cekat dapat memberikan dampak berupa perubahan lingkungan mulut, peningkatan jumlah plak yang dapat menyebabkan karies, penyakit periodontal seperti gingivitis. Menjaga kebersihan mulut dengan baik merupakan tantangan bagi siapapun terutama pengguna alat ortodontik cekat. Kelebihan komposit disekitar dasar bracket merupakan faktor yang 
Hubungan lama penggunaan alat ortodontik cekat terhadap akumulasi plak dan ph saliva mahasiswa FKG-UMI tahun 2017

dapat menyebabkan akumulasi plak karena permukaan kasar dan adanya celah terhadap retensi plak dan mengganggu kebersihan mulut. ${ }^{7,8}$

Menurut teori, waktu perawatan alat ortodontik bervariasi sesuai dengan kesulitan kasusnya. Rata-rata perkiraan waktu perawatan adalah 2 tahun tetapi pada kenyataan waktu perawatan seringkali $50 \%$ lebih lama dari waktu yang diprediksikan, biasanya ini terjadi pada remaja dan bahkan penggunaan alat ortodontik ini biasa lebih lama lagi pada orang dewasa karena kasusnya yang lebih sulit.

Penelitian yang dilakukan oleh Mantiri Cecilia, S, dkk pada tahun (2013) menunjukkan bahwa pada mahasiswa penggunaan alat ortodontik cekat di Fakultas Kedokteran Gigi Universitas Sam Ratulangi Manado, hasil penelitian yang diperoleh menunjukkan bahwa mahasiswa yang menjadi subejek penelitian memiliki kebersihan mulut pada kategori baik hingga sedang. ${ }^{1}$

Kesehatan rongga mulut memegang peranan yang penting untuk masalah satu komponen hidup sehat yang penting. Kebersihan mulut yang tidak dipelihara dengan baik akan menimbulkan berbagai penyakit dirongga mulut. Kebersihan mulut sangat ditentukan oleh perilaku. Pemeliharaan kebersihan mulut yang tidak benar akan menyebabkan mudahnya menumpuknya plak, material alba, dan kalkulus yang akan akhirnya akan merugikan kesehatan periodontal. Kebersihan mulut yang jelek dapat menyebabkan terjadinya komplikasi seperti gingivitis, halitosis, xerostomia, pembentukan plak dan karies gigi. $^{9}$

Menurut tabel 5. hasil pemeriksaan $\mathrm{pH}$ saliva pada mahasiswa Fakultas Kedokteran Gigi Universitas Muslim Indonesia menunjukkan bahwa $\mathrm{pH}$ saliva pengguna alat ortodontik $\leq 12$ bulan yaitu sebesar $(2,6 \%)$ tergolong normal, $(28,2 \%)$ tergolong asam, dan $(0 \%)$ tergolong basa, sedangkan yang menggunakan alat ortodontik $>12$ bulan yaitu sebesar (2,6\%) tergolong normal, $(66,7 \%)$ tergolong asam, dan $(0 \%)$ tergolong basa. Berdasarkan hasil uji statistik dengan menggunakan uji Independent Samples Test, diperoleh nilai $p=0,001 \quad(<\alpha=0,05)$, dengan demikian diputuskan $\mathrm{H}_{0}$ ditolak dan $\mathrm{H}_{a}$ diterima yang artinya ada hubungan lama pengunaan alat ortodontik cekat terhadap $\mathrm{pH}$ saliva mahasiswa FKGUMI Tahun 2017. 
Hubungan lama penggunaan alat ortodontik cekat terhadap akumulasi plak dan ph saliva mahasiswa FKG-UMI tahun 2017

Pada salah satu penelitian yang dilakukan oleh Sepideh Arab, dkk pada tahun (2016), hasil penelitian yang didapatkan bahwa desain yang rumit dari piranti ortodontik cekat mempengaruhi kebersihan rongga mulut dengan mempengaruhi beberapa faktor, salah satunya yaitu perubahan pH saliva. ${ }^{10}$ Perubahan $\mathrm{pH}$ saliva dalam rongga mulut menyebabkan terjadinya demineralisasi pada lapisan email gigi yang meningkatkan kerentanan terhadap karies gigi. Penelitian yang sejalan dilakukan oleh Lara-Carillo, dkk., (2010), menyatakan bahwa perawatan dengan menggunakan ortodontik cekat dapat merubah keadaan rongga mulut, menurunkan $\mathrm{pH}$ saliva selama perawatan ortodontik. Perawatan ortodontik cekat tetap direkomendasikan akan tetapi tetap menjaga kesehatan rongga mulut. ${ }^{4}$

Menurut Rammadhan dkk. (2016) mengatakan bahwa salah satu usaha untuk mencegah dan menaggulangi masalah kesehatan gigi adalah melalui pendekatan pendidikan kesehatan gigi. Pendidikan kesehatan gigi yang disampaikan kepada seseorang diharaapkan mampu mengubah perilaku dan mendapatkan pengetahuan kesehatan gigi individu dari perilaku yang tidak sehat kearah perilaku sehat. Selain itu kesehatan gigi dan kebersihan mulut yang baik juga dipengaruhi oleh peran dokter gigi dalam memberikan motivasi dan intruksi selama perawatan ortodontik cekat. ${ }^{11}$ Dokter gigi perlu memberikan motivasi dan intruksi yang benar sejak awal sampai akhir perawatan ortodontik cekat sehingga pasien lebih peduli terhadap kesehatan gigi dan mulutnya. ${ }^{1}$

\section{KESIMPULAN}

Berdasarkan hasil penelitian yang telah dilakukan di FKG-UMI tahun 2017, maka dapat disimpulkan bahwa : Distribusi dan frekuensi lama penggunaan alat ortodontik cekat mahasiswa Fakultas Kedokteran Gigi Universitas Muslim Indonesia terdapat 39 responden, berdasarkan lama penggunaan ortodontik cekat pada penggunaan $\leq 12$ bulan yaitu $(30,8 \%)$ dan penggunaan ortodontik cekat $>12$ bulan yaitu $(69,2 \%)$. Dengan akumulasi plak skor tertinggi sedang (skor 25-50) yaitu $(74,4 \%)$ dan $\mathrm{pH}$ saliva skor tertinggi asam (skor 0,0-6,9) yaitu $(94,9 \%)$. Sehingga di dapatkan terdapat hubungan lama penggunaan alat ortodontik cekat terhadap akumulasi plak dan terdapat hubungan 
Hubungan lama penggunaan alat ortodontik cekat terhadap akumulasi plak dan ph saliva mahasiswa FKG-UMI tahun 2017

lama penggunaan alat ortodontik cekat terhadap $\mathrm{pH}$ saliva.

Penggunaan ortodontik cekat perlu memahami dan menyadari dampak dari perawatan ortodontik cekat pada kesehatan rongga mulut. Sehingga kebersihan mulut merupakan aspek yang sangat penting dalam menjalankan perawatan ortodontik cekat. Kesadaran dalam menjaga kebersihan mulut akan meminimalisir terjadinya resiko yang timbul oleh pemakaian ortodontik

\section{DAFTAR PUSTAKA}

1. Mantiri SC, et al. Status kebersihan dan Status Karies Gigi Mahasiswa Pengguna Alat Ortodontik Cekat. Jurnal e-Gigi, 2013;1(1).

2. Sakinah N, et al. Peningkatan Lebar Lengkung Gigi Rahang Atas Melalui Perawatan Ortodontik Menggunakan Sekrup Ekspansi. Jurnal e-Gigi, 2016;1(1).

3. Mahardika R, et al. Efektifitas Perendaman Alat Ortodontik Lepasan Dengan Bahan Pemebersihan Gigi Tiruan Terhadap Perubahan pH Saliva Pada Pasien di RSGM-P. Jakarta: FKG UI, 2013.

4. Carillo LE, et al. Effect of Orthodontic Treatment On Saliva Plaque, and The Levels Of Streptoccos Mutans and Lactobacillus. 2010;15 (6):924-929.
5. Jayanti AT. Hubungan Lama Penggunaan Piranti Ortodontik Cekat Dengan Status dan Kebutuhan Perawatan Periodontal Pada Mahasiswa FGK-UMI Makassar Tahun 2017 (Skripsi). Makassar: Fakultas Kedokteran Gigi Universitas Muslim Indonesia, 2017

6. Lastianny PP. Dampak Pemakaian Alat Ortodontik Tehadap Kesehatan Jraingan Periodontal, 2012.

7. Marchelina RAG, et al. Status Kesehatan Gingiva Pengguna Alat Ortodontik Cekat di SMA Negeri 1 Manado. 2016;5(I).

8. Oktaviani V and Oedijani S. Perbedaan Indeks Hygiene Oral dan $\mathrm{pH}$ Plak Kelompok Pemakai dan Bukan Pemakai Pesawat Ortodontik Cekat, Jurnal Kedokteran Diponogoro, 2016;5(1): 54-55.

9. Basuni C. Kedokteran Gigi Klinis ed. 2. Yogyakarta: CV. Quantum Sinergis Media, , 2014,p. 51

10. Arab S, et al. Effect of Fixed Orthodontic Treatment On Saliva Flow, $\mathrm{pH}$ and, Microbial count. 2016;3(1): 18-19.

11. Ramadhan A, et al, Hubungan Tingkat Pengetahuan Kesehatan Gigi dan Mulut Terhadap Angka Karies Gigi di SMPN 1 Marabahan. Dentino Jurnal Kedokteran Gigi, 2016;I(2). 